Longitudinal study

\section{Hospital admission may increase the risk of potentially inappropriate prescribing among older primary care patients}

10.1136/ebnurs-2019-103083

Manuel Schwanda, BSc, MScN, RN, ${ }^{1}$ Rita Gruber, BScN, MSc, $\mathrm{RN}^{1,2}$

${ }^{1}$ Department of Health Sciences, St. Pölten University of Applied Sciences, St. Pölten, Austria, Lower Austria, ${ }^{2}$ School of Nursing, Bildungszentrum Diakonissen, Linz, Austria

Correspondence to: Manuel Schwanda, BSc, MScN and RN, St. Pölten University of Applied Sciences, Austria; manuel.schwanda@fhstp.ac.at

Commentary on: Pérez T, Moriarty F, Wallace E, et al. Prevalence of potentially inappropriate prescribing in older people in primary care and its association with hospital admission: longitudinal study. BMJ 2018;363:k4524. doi: 10.1136/bmj.k4524.

\section{Implications for practice and research}

- The process of medication reconciliation could be a strategy to reduce the risk of potentially inappropriate prescribing among older primary care patients.

- There exists a significant association between hospital admission and potentially inappropriate prescribing, but further research regarding medication management across all involved healthcare professions is needed.

\section{Context}

A crucial approach of the WHO's third global patient safety challenge is to identify potentially inappropriate prescribing, associated with adverse drug events, hospital admissions and reduced quality of life. ${ }^{1}$ The omission of beneficial drugs, the use of drugs with a drug-drug interaction, the use of incorrect drug dosages and/or prescribing durations and the prescribing of drugs primarily associated with risks are recognised potentially inappropriate prescribing methods. The prevalence rate of potentially inappropriate prescribing detected via the Screening Tool for Older Persons' Prescription (STOPP) criteria varies between European countries and is up to 51\%. This is congruent with the present study, but the problem is recognised globally. ${ }^{2}$

\section{Methods}

The purpose of the study ${ }^{3}$ was to determine the annual prevalence of potentially inappropriate prescribing in older Irish people and to demonstrate an association with hospital admission by using 45 criteria of STOPP version 2 . The longitudinal study used retrospective data from the accredited patient management system Socrates between 2012 and 2015. A total of 38229 patients from 44 general practices were included in the 4-year study period. Statistical analyses regarding the annual prevalence of potentially inappropriate prescribing (eg, SD, IQR, absolute and relative frequencies), the association between potentially inappropriate prescribing and hospital admission (eg, Prentice, Williams and Peterson model, OR/HR and 95\% CI), potentially inappropriate prescribing before and after admission to hospital (eg, paired sample tests) as well as sensitivity analyses were applied. P value $<0.05$ was defined as statistically significant.

\section{Findings}

The mean age of the participants in 2012 was $76.8( \pm 8.2)$ years and 57\% were female. In 2012, a total of 45.3\% (13940/30753) of patients received one, to more than three, inappropriate prescriptions; in 2015, the given prevalence was 50.97\% (14823/29077). Up to 15\% ( $\mathrm{n}=4537)$ of patients had at least one hospital admission and their risk of having any potentially inappropriate prescription increased significantly after admission ( $\mathrm{p}<0.05$; OR 1.72; CI 1.63 to 1.84). Overall, the analyses showed a significant association between hospital admission and potentially inappropriate prescribing.

\section{Commentary}

This study focused on the association between hospital admission and potentially inappropriate prescribing among older Irish people. This study further outlined whether inadequate prescribing is more probable after hospital admission compared with before. The authors conducted and reported a very well-designed investigation by using the Strengthening the Reporting of Observational studies in Epidemiology (STROBE) statement as suggested by the equator network (www.equator-network.org). This checklist includes 22 items and was developed to support scientists in reporting observational studies transparently. Furthermore, the sample size was large and the researchers used the latest version of the STOPP criteria to evaluate inappropriate prescribing, whereby merely 45 (56\%) of the 80 criteria, which this tool normally includes, were used. ${ }^{3}$ In addition, the use of STOPP criteria, which were developed by a panel of expert prescribers, is suggested for older primary care patients and is described as a validated screening tool to detect potentially inappropriate prescribing in older people. ${ }^{23}$

Inappropriate prescribing of medications is a common problem at care transition and associated with adverse drug events. ${ }^{4}$ Therefore, the process of medication reconciliation could be a strategy to reduce adverse events. The objective of this process is to create the most accurate list of medications (including herbals, vitamins, nutritional supplements, over-the-counter drugs, etc) a patient is taking. Therefore, five steps are suggested: First, compile a list of the patient's medication before hospital admission; then list currently needed medication (in hospital) and compare them in step three with the list of medications taken by the patient; after that generate a new list of medications based on the comparison. Step five is to share and discuss the updated list with the patient and/or to the caregivers. ${ }^{5}$ An updated review of medications presents evidence for medication reconciliation/review in primary care to reduce medication discrepancies at care transition whereby pharmacists, nurses and primary care physicians should collaborate. ${ }^{6}$

Competing interests None declared.

Provenance and peer review Commissioned; internally peer reviewed.

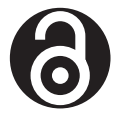

\section{OPEN ACCESS}

Open access This is an open access article distributed in accordance with the Creative Commons Attribution Non Commercial (CC BY-NC 4.0) license, which permits others to distribute, remix, adapt, build upon this work non-commercially, and license their derivative works on different terms, provided the original work is properly cited, appropriate credit is given, any changes made indicated, and the use is non-commercial. See: http://creativecommons.org/licenses/by-nc/4.0/.

๑ Author(s) (or their employer(s)) 2020. Re-use permitted under CC BY-NC. No commercial re-use. See rights and permissions. Published by BMJ.

\section{Check for updates}




\section{References}

1. Avery AJ, Coleman JJ. Tackling potentially inappropriate prescribing. Opportunities to intervene are often missed. BMJ 2018;363:k4688.

2. Abeyratne R. Inappropriate prescribing in the older population, GM. 2014. https:// www.gmjournal.co.uk/inappropriate-prescribing-in-the-older-population

3. Pérez T, Moriarty F, Wallace E, et al. Prevalence of potentially inappropriate prescribing in older people in primary care and its association with hospital admission: longitudinal study. BMJ 2018;363:k4524.
4. Redmond P, Grimes TC, McDonnell R, et al. Impact of medication reconciliation for improving transitions of care. Cochrane Database Syst Rev 2018;8:1465-858.

5. Barnsteiner JH, Hughes RG. Medication Reconciliation. Patient Safety and Quality: An Evidence-Based Handbook for Nurses. Rockville (MD): Agency for Healthcare Research and Quality (US), 2008:459-72.

6. Kee KW, Char CWT, Yip AYF. A review on interventions to reduce medication discrepancies or errors in primary or ambulatory care setting during care transition from hospital to primary care. J Family Med Prim Care 2018;7:501-6. 